University of Rhode Island

DigitalCommons@URI

Open Access Master's Theses

1984

\title{
Social Facilitation and the Type A Behavior Pattern
}

Kim H. Knight

University of Rhode Island

Follow this and additional works at: https://digitalcommons.uri.edu/theses

\section{Recommended Citation}

Knight, Kim H., "Social Facilitation and the Type A Behavior Pattern" (1984). Open Access Master's

Theses. Paper 1634.

https://digitalcommons.uri.edu/theses/1634

This Thesis is brought to you for free and open access by DigitalCommons@URI. It has been accepted for inclusion in Open Access Master's Theses by an authorized administrator of DigitalCommons@URI. For more information, please contact digitalcommons-group@uri.edu. 
SOCIAL FACILITATION AND THE

TYPE A BEHAVIOR PATTERN

BY

KIM H. KNIGHT

A THESIS SUBMITTED IN PARTIAL FULFILIMENT OF THE REQUIRFMENTS FOR THE DEGREE OF

MASTER OF ARTS

IN

PSYCHOLOGY

UNIVERSITY OF RHODE ISLAND

1984 


\section{Abstract}

A laboratory study was conducted to examine the Type A behavior pattern as it affects social facilitation on a hidden-word task. Type A and Type B individuals completed the word task either alone, with an individual who purportedly had already completed the task observing, or with an individual who purportedly would soon complete the task observing. Additionally, half of the subjects were given competitive instructions while the other subjects were not. The results indicated that Type As who completed the task alone showed greator social facilitation effects than did Type Bs in this condition. The results are discussed in terms of evaluation apprehonsion, and it is suggested that future research should investigate Type As' perception of the task situation as it relates to this concept. 
I am very grateful to the many people who made the completion of this thesis possible. My sincerest thanks are extended to my major professor, Dr. Jerry I. Cohem, for giving mo the autonomy I desired, while also offering guidance and helpful comments in the development and completion of this study. I also wish to thank my committee members, Anita Creamer and Dr. Albort J. Lott, whose suggestions wore very helpful and greatly appreciated. Additionslly, I am grateful to Dr. Peter Moronda and Dr. John Stevenson, whose comments on the proposal for this study wore very useful.

I wish to express my appreciation to the students who served as confedorates in this study. These were Mary Connelly, Barry . Fitzgerald, Marie Flahorty, Andrea Gammino, James Grogory, Amy Skrocki, and Phyllis Winklor. Their conscientious and skillful assistance mado my task much easier.

Two of my undergraduate professors, Dr. Donald P. Corriveau and Dr. Morton H. Elfenboin, are indirectly responsible for the completion of this thesis. Dr. Corriveau first introduced mo to tho Typo A bohavior pattorn, for which I thank him. I am ospecially indebted to Dr. Elfonbein, who was instrumental in my desire to become a researcher.

Finally, I want to express do deepest gratitude to my paronts. They instilled in me an appreciation of education, and have provided enormous support in helping me to achievo my goals. 
I. Abstract -

II. Introduction - 1

III. Mothod - 12

A. Subjects - 12

B. Stimulus Materials - 13

C. Apparatus - 16

D. Fxperimental Design

E. Procedure -

IV. Rosults -

A. Training Trials - 21

1. Latoncios - 21

2. Errors - 23

B. Performance Trials - 23

1. Latencios -

2. Solutions - 23

C. Extinction Trial

1. Latency - 24

2. Errors - -26

D. Postsession Questionnaire - 28

V. Discussion - 34

VI. References - 39

VII. Appendix 42 


\section{LIST OF TABLES}

TABLE

1 Stimulus Presentations and Their Solutions - -

2 Latency Moans for Training Trials -

3 Number of Errors Made on Extinction Trial Across

Experimental Conditions -

4 Means for Postsossion Itom: How Intoresting Task Was -------31

5 Means for Postsossion Item: How Important It Was to Do Well-33 


\section{LIST OF FIGURES}

FIGURE

PAGE

1 Mean Solutions of Performance Trials for Type X Peor

Presence Interaction - 25

2 Mean Latencies for Extinction Trial for Competition

Presence X Peer Presence Interaction - 
Social Facilitation and the Type A Behavior Patterm

Social facilitation is a phenomenon which has been of interest to social psychologists for many years, dating back to Triplett's work in which he discovered that children winding fishing reels while coacting with other childron performed faster than childron winding reels alone (1897). As defined by Zajone (1965), social facilitation refers to situation in which an individual working in the presence of other people experiences a state of general arousal, and as a consequence exhibits improved performance of learned or dominant responses, and impairment of unloarnod, complex tasks.

Zajone (1965) proposed that the mere presence of others is a drive or general source of arousal which will lead to social facilitation or inhibition, depending on the nature of the task. Various studies ( $0 . g .$, Markus, 1978; Zajonc \& Salos, 1966) have found empirical support for this theory. Zajonc and Sales (1966) omployed a psoudorecognition task in which subjects were first exposed to stimulus words and were asked to repeat some of these words once, others twice, and still others 4,8 , or 16 times. In this manner, the habit strength of the stimulus words differed, thus placing them in competition with one another. The subjects were then told that the words they had been pronouncing would be flashed upon a screen one at a time and that although the presentation might be brief, they were to call out the exposed word. In actuality, only a wordlike stimulus that was unrecognizable was flashed. The results 
showed that the presence of a passive audience increased the tendency of the more frequently exposed words to be emitted at the expense of the weaker habit strength words, as compared to the conditions in which no audience was presont.

The study performed by Markus (1978) also found support for the theory that the mero presence of others is sufficient to influence an individual's performance. The tasks employed were dressing and undressing in familiar (simple task) and unfamiliar (complex task) clothing. The performance times for these tasks were compared for subjects who dressed either alone, in the presence of an inattentive person, or in the presence of an attentive observer. The results indicated that as compared to tho alone condition, both audience conditions onhanced performance on the woll-leamed task (familiar clothing), while impairing performance on the more complex task (unfamiliar clothing). Therefore, the mere presence of others was considered sufficient to cause social facilitation and social inhibition offects.

Other researchers have not been content with the mero presence theory, and have instead proposed alternative theories ( Cottrell, 1968; Cottrell, 1972; Cottrell, Wack, Sekerak, \& Rittle, 1968; Henchy \& Glass, 1968; Sanders, Baron, \& Moore, 1978). Cottrell (1968) proposed that rather than the mere presence: of others being sufficient to enhance the omission of dominant responses, those prosent mast actually create anticipations of positive. or negative outcomes. Cottrell contended that rather than the presence of others being an innate source of drive as assumed by Zajonc (1965), 
the individual's arousal was due to a learmed source of drive. In other words, the individual has acquired a sonse of evaluation apprehension in the presence of others.

Cottrell et al. (1968) tested this theory utilizing the pseudorecognition task used by Zajonc and Sales (1966). Once again the first part of the study was to establish a set of verbal habits of different strengths for the ten nonsense words. After this phase was completed, subjects were instructed to call out the word they believed they saw flashed on a screen for a brief time. Subjects performed the task under one of three conditions: alone in the room; audience condition in which two interested spectators watched; and a mere presence condition in which two spectators wore blindfolds, thereby preventing them from observing the subject and stimuli. Results of the study indicated that the presence of an audience onhanced the emission of dominant responses, but that the mere presence and alone conditions did not.

Further support for the evaluation apprehension theory comes from Henchy and Glass (1968). Using the pseudorecognition task previously utilized by Zajonc and Sales (1966), subjects were assigned to one of four experimental conditions. These were an alone condition, an expert together condition in which two individuals described as experts in human learning observed, a nonexpert condition in which two individuals described as students observed, and an alone recorded condition in which subjects were led to believe that their performance on the task was being recordod for later ovaluation by human learning 
specialists. Analysis of the data showed that for subjects who believed their performance was boing ovaluated (expert together and alone rucorded conditions), the emission of dominant responses was enhanced. Concurrently, the subordinate responses were emitted slightly more frequently in the alone and nonexpert conditions. The alone and nonexpert conditions did not differ significantly, thereforo supporting the evaluation apprehension hypothesis, rather than the mere presence theory.

The findings of Cohen and Davis (1973), however, suggested that the mere presence of an audience did affuct performance, and that evaluation apprehension served to exacerbate this effect. These researchers utilized a-hidden-word task in which the subjects were instructed to find a word ombedded in a string of letters. Aftor acquiring a set solution (dominant response) during the first 13 word problems where only one solution was possible, the subject was presented with additional probloms in which the set solution or a more direct and simpler solution (subordinate response) could be found. If the subject continued to use the set solution, then social facilitation could bo said to bo occuring. Their results indicated that all audience conditions (evaluative and nonevaluative) gavo more set solutions than the alone conditions. In addition, for conditions in which the subjects were told their porformance would lator be evaluated and discussed, more set solutions were given than in the observation without ovaluation conditions. Therefore, this study supported the theories of both $\mathrm{Zajonc}$ and cottrell, showing that mere presence was 
enough to cause sxcial facilitation, whilo ovaluation apprehension increased this effect.

Sanders, Baron, and Moore (1978) proposed yet another theory to account for social facilitation. They stressed the process issue in explaining why drivelike effects on behavior occur. The argument presented by these researchers was that drive effects in social facilitation/inhibition reserrch result from other individuals distracting the subject from ongoing task activity and attending to the distractor. This conflict, rather than being a disruptive influence, is said to be a source of drive which facilitates performance on simple tasks.

In addition, Sanders et al. (1978) hypothesized that subjects are distracted in large part bocause they are interested in obtaining social comparison information regarding their performance. They suggested that a subject might compare one's own performance with that of a coactor, or that it might involve comparing one's opinion of one's performance to the opinion held by the audience. Sanders et al. (1978) set about to test their distraction-conflict theory by conducting two experiments.

In Experiment One, subjects performed either a simple or complex copying task alone or with a coactor, and the experimenters manipulated the pressure to engage in social comparison. In the no comparison pressure condition, subjects were told that they were performing the copying task so that they could give the experimenters their opinion of it. Conversely, in the comparison pressure con- 
dition, they were told that their ability to defer gratification would be measured. Based on the distraction-conflict theory, it was hypothesized that the comparison pressure condition should lead to enhanced performance on the simple task and impaired performance on the complex copying task. This was in relation to the no comparison pressure condition. As predicted, the results indicated that for the simple task, coacting subjects performed significantly better than those subjects working alone, but only in the comparison pressure condition. In addition, it was found that the mere presence of coactors was not onough to cause social facilitation when subjects worked in the no comparison pressure condition.

Experiment Two manipulated the comparison information that was available. More specifically, subjects performed either a simple or complex copying task in one of three conditions: alone; together different wherein a coactor working on a different task than the subject was present; and together same, in which a coactor performing the same task as the subject was present. It was hypothesized that only where the comparison information was relevant (together same condition) would there bo social facilitation of the simple task and impairment of the complex task. The results of this experiment were that social facilitation occured only when coactors worked on the same task as the subject.

Therefore, both experiments of Sanders et al. (1978) lent support to the distraction-conflict theory, showing that the distracting activity of comparing one's performance with that of a coactor lod 
to improvement on a simple task. At the same time, the study did not find support for the mere presence theory of Zajonc.

Recently, two theories which do not attribute social facilitation/ inhibition effects to a drive source have beon proposed (Bond, 1982; Carver \& Scheier, 1981). Bond (1982) modified the Cottrell (1968) explanation by contending that evaluation apprehension did not serve as a source of generalized drive. Instead, Bond offered a self-presentational account of social facilitation wherein the desire to maintain esteom and avoid ombarrassment motivated performance facilitation.

According to Bond (1982), the drive theories and self-presentational hypothesis also differ with regard to item complexity. With the drive theories, it is proposed that a simple task will show facilitation effects while a complex task will show impaiment effects. The self-presentational view holds that the complexity of the task will only affect performance insofar as it carries information about the competence of the task performer. For example, if a predominantly easy task is performed and the individual infers no failure, then a complex itom embodded within this task should also show social facilitation effects in the presence of another individual. However, if failure is inferred from the performance on a predominantly difficult task, the individual should experience embarrassment in the presence of another individual and exhibit social impairment on both simple and complex items within that task. In other words, the self-presentational theory prodicts task-wide effects based on aggregate 
task difficulty, whilo tho drive thoories predict moro itom-specific effects.

To test this theory, Bond used two verbal learning tasks and subjects porformed either alono or in the presence of an observor. One task was a difficult ono which contained a few simple items, and tho other was an easy task that included a few complex items. It was hypothesized that facilitation would occur on the task that was primarily simple, with an observer's presence not impairing the learning of the complox items ombedded within this task. At the same time, the presence of an observor was expocted to impair the loarning of simplo items ombedded within the difficult task. Both hypotheses wore supported, suggesting that the solf-prosentational view may have some validity.

Carvor and Scheier (1981) have suggested that rather than tho presence of an audience leading to heightened drive, it actually causes subjects to direct more attention to themselves. It is during this state of self-focus that subjects compare their presont behavior to a previously ostablished standard, and performance facilitation or inhibition results. In other words, a cybernetic feedback loop is ongaged wherein a standard of porformance is set, and audience presence or self-directed attention surves to remind subjects of this standard thereby leading to conformity. to the standard, or facilitation (assuming a well-loarned task is being performed). An assumption of this theory therefore, is that since self-focus is the mediating condition for performance facilitation or inhibition, then it should 
be witnessed even in asocial conditions if subjects are made self aware.

Carvor and Scheier (1981) conducted an experiment to test this theory. Subjects performed a copying task either alone, with a mirror positioned directly in front of them, or with the experimenter indicating a desire to watch and sitting directly across from them. In line with the theory, it was predictod that onhanced performance would occur when self-focus was increased by either the mirror or the presence of the observing experimenter. The results indicated that subjects in both the audiunce and mirror conditions showed performance facilitation, supporting the theory. As with the selfpresentational theory, however, this theory has not been subject to mach experimentation at this point.

While much of the research in this area has been concerned with theory testing, fewer studies have considered personal attributes of the evaluator or coactor. Cohen and Davis (1973) did not find statistically significant different social facilitation effects when comparing the presence of a peer with that of a faculty member as evaluators. However, Gastorf, Suls, and Sanders (1980) found that characteristics of both the subject and the coactor were variables which affectod social facilitation.

More specifically, Gastorf et al. (1980) examined subjects who exhibited the Type A behavior pettern. Type A is a coronary-prone behavior pattern, and those individuals exhibiting it are characterized by: 1) competitive achievement striving; 2) aggrossive- 
ness; and 3) an exaggerated sense of time urgency (Friedman \& Rosenman, 1959; Friedman \& Rosenman, 1974; Glass, 1977). Type B individuals are relatively froe of these characteristics.

In the Gastorf et al. (1980) study subjects completed either a simple or complex copying task either alone, with a similar coactor, or with a superior coactor. In the similar coactor condition, the subject worked on the task while a confederato who was described as having the same amount of practice as the subject performed the task at the same rate. In the superior coactor condition, the subject performed the task in the presence of a confederate who also worked on the same task, but who was described as having had more practice as the subject and actually worked at a faster rate than the subject. In the two coacting conditions the subjects were told that their performance would be evaluated relative to the other subject (confederate). Subjects in all conditions were told that their performance would be ovaluated relative to established norms.

Results of the Gastorf et al. (1980) study indicated that for Type A individuals, the presence of either a similar or superior coactor facilitated their performance on the simple task, while impairing performence on the complex task. For Type Bs, the presence of coactors did not significantly affect their purformance, although there was a slight tendency for their performence to be onhanced in the presence of similar coactors while working on the simple task. While Gastorf et al. (1980) found that Type As reported greater feelings of distraction than Type Bs when coactors were introduced and from this 
intimated that a viable explanation for the social facilitation offocts was distraction-conflict, there was a confound in the design of the study. To be more specific, the instructions to the subjects in the coacting conditions implied competition. Further, Type As reported competitive feelings while in the presence of a similar or superior coactor and Type Bs reported competitive feelings when coacting with a similar opponent. Therefore, it is impossible to ascertain whether the foelings of distraction caused by the presence of a coactor, or the self-reported competitive feelings were responsible for the social facilitation effects.

Thus, a major purpose of the present study was to extricate competition from mere evaluation apprehension or distraction, in order to examine the cause of social facilitation of Type A individuals. While the Gastorf et al. (1980) study utilized coactors who performed the task simultaneously with the subjects, this study utilized an observing confederate who was believed to be a past (experienced) or future (inexperienced) subject of the. study. Compotition was also manipulated such that half of the subjects believed that they were competing for a $\$ 5.00$ prize, while the other half were given no such inducement.

Consistent with the results of Gastorf ot al. (1980), it was predicted that Type As would show greater social facilitation effects than Type Bs. Additionally, the prediction that Type As would show greater social facilitation effects when a peer who had already completed the task was prosent (experienced) than when an inexperienced 
peer soon to complate the task was present, was mado. It was also expected that when the task was clearly defined as competitive, greater social facilitation effects would be observed. This was expected particularly for Type As who are reportedly spurred on by competition ( Gotay, 1981).

Since social facilitation is at the core of human social behavior in many instances, it seemed imperative to examine those conditions which serve to enhance it. Similarly, it was a purpose of this study to test whether As would continue to emit set responses under all conditions of the present experiment (even while alone). Friedman and Rosenman (1974) reported that in the interest of saving time, Type As indulge in stereotyped responses and actions which can subvert their creative attributes. If this is true, the nature of their cognitive functioning may be altered such that at times their behaviors may not take into account the situation and may indeed be rigid and nonadaptive. In these instances, social facilitation, or the emission of dominant responses may be detrimental, and deserves examination.

\section{Method}

Subjects

The subjects were undergraduate students recruited from general psychology classes at the University of Rhode Island in the spring and fall of 1982 and spring of 1983. They received course credit for their participation.

All subjects completed the Jenkins Activity Survey (JAS)Form T ( Krantz, Glass, \& Snyder, 1974). Based upon norms established 
with 428 students at the University of Rhode Island, who took the general psychology class in the fall of 1981 , subjects were classified as either Type A or Type B. Subjects were rendomly assigned to the 12 conditions such that an equal number of males, females, Typo As, and Type Bs wore in each cell.

One female Type A subject who had been assigned to the inexperienced peer present/competition condition asked that the confederate who entered the room not be allowed to watch her. The confederate loft imediately with an apology, and the subject completed the task, but the situation made it necessary to disregard her results.

The final sample consisted of 144 subjects, with an equal proportion of males and females, and of As and Bs.

\section{Stimulus Materials}

Jenkins Activity Survey. The student version of the JAS (Krantz, et al., 1974), designed to differentiate Type A individuals from Type Bs, was administered to each potontial subject. The JAS is a twontyone item multiple-choice questiomaire which has been shown to distinguish Typo As from Type Bs ( Jenkins, Rosenman, \& Zyzanski, 1974; Kenigsberg, Zyzanski, Jenkins, Wardwell, \& Licciardello, 1974). Scores on the JAS can range from zero to twenty one, with the higher score indicating greater degrees of the Type A personality.

The scoring procedure with this form is to do a median split, and assign those whose scores fall below the median the Type B title, and those whose scores fall above are referred to as Type As. In large samples of undergraduates the median of the JAS falls between 7 
and 8 (Glass, 1977). The administration of the JAS to a University of Rhode Island general psychology class $(n=428)$ in the fall of 1981 indicated that seven was the median. Those subjects with a score at the median were randomly assigned an $A$ or $B$ title.

Although there has been little effort to collect systematic data on the test-rotest reliability of the student version of the JAS, the adult version of the scale has shown a test-retest reliability of .65 across periods of up to four years ( Jenkins, ot al., 1974). In view of the fact that Type $A$ is a behavior pattern and thus is dependent on environmental stimuli to bring about its occurence, this reliability is reasonable since one's lifestyle is subject to change over such a time period. (see Appendix).

Hidden-word task. The hidden-word task developed and omployed by Cohen and Davis (1973) was utilized. It has been used in several studies ( Cohen \& Davis, 1973; Cohen; 1979; Cohen, 1980; Elliot \& Cohen, 1981), and has demonstrated validity for showing social facilitation offects.

With this task, the subject must find a word ombedded in a string of letters without changing the order of the letters. During the training phase, 13 hidden-word problems are presented to the subjects. These 13 problems are constructed such that only one solution can be achieved, and that is done by starting with the first letter and then taking every other letter ( see Table 1). In this manner, a set solution ( dominant response), or Einstellung, is established. The next four problems are the performance trials, and are con- 
Table 1

Stimulus Prosentations and Thoir Solutions

\begin{tabular}{cll} 
Order of presentation & Stimulus sequence & Solution word \\
\hline Practice trial & CPATRMD & CARD \\
Training Phase & & \\
1 & GZOQART & GOAT \\
2 & IIORLZF & WOLF \\
3 & DZEPEWR & DEER \\
4 & BOUFLML & BULL \\
5 & MKUGLMF & MULE \\
6 & FBIQSAH & FISH \\
7 & SGWGIBNQE & SWINE \\
8 & HXATWOK & HAWK \\
9 & BXESAUR & BFAR \\
10 & SJNGAQKSE & SNAKE \\
11 & MZIPCOE & MICE \\
12 & LHISOJN & LION \\
13 & SVHREKEQP & SHEEP \\
14 & & \\
15 & SXNJAWILI & SNAII/WIII \\
16 & HDOORJSWE & HORSE/DOOR \\
17 & SZTOOKRBK & STORK/TOOK \\
18 & TKIBGBEER & TIGER/BEER \\
Performance Phaso & GNEVERZOE & NEVER (EVER) \\
Extinction & &
\end{tabular}


structed such that each solution is obtainable through the trained set or through an alternative solution. Obtaining the alternative solution ( subordinate response) can be done by a more direct method than the set solution (dominant response). The last problem, or extinction trial, requires that the subject break set in order to solvo it correctly. Apparatus

A Kodak Carousel Slide Projector was used to project the stimulus presentations on the wall in front of the subject. It was placed on a table in front of the experimenter, 12 feet from the wall.

A Lafayette Yulti-Function Digital Timer was used to time the subjects' responses. It, too, was placed on the table with the projector. As soon as the slide was projected for the subject, the experimenter pushed the "start" button on the timer. When the subject called out a response, the experimenter pushed a "stop" button and recorded the time by hand.

Experimental Design

Twelve subjects ( 6 females, 6 males) were randomly assigned to each of the 12 conditions, resulting from the 2 ( Type A or Typo B) X 2 (Competition, No Competition) X 3 (Inexperienced Peer, Experienced Peor, Alone) design.

\section{$\underline{\text { Procedure }}$}

Two subjects were scheduled for each hour session. One subject completed the JAS first, while the other subject worked on the hidden-word task. After being greeted at the laboratory by the 
experimenter, it was explained to the participants that there would be these two tasks to complete. One of seven (five females and two males) confederates was introduced to the subject as a research assistant who would be administering the JAS. The research assistant proceeded to take one of the subjects (selected at random) downstairs to a testing cubicle, which insured privacy and quiet. The research assistant instructed the subject to read the instructions and to answer every question, and then left the subject alone while the JAS was being completed. The assistant had been instructed to keep the subject downstairs for at least 20 minutes so that $s / h e$ would not hear the first subject completing the hidden-word task. As soon as this time was up and the subject had completed the JAS, the assistant escorted the participant back upstairs for the word task. At this time, the first subject who had completed the word task went downstairs with the assistant, while the second subject did the word task. In this way, the order of the JAS and hidden-word task was counterbalanced.

Debriefing sheets were prepared and handed out for the JAS and for the word task. If the subject still had questions unanswered by these sheets, the experimenter did her best to answer them.

Hidden-word task. The first subject who remained upstairs to complete the word task was Ied into the laboratory, where $\mathrm{s} / \mathrm{he}$ was instructed to sit at a tablo approximately six feet from the wall where the stimulus presentations appeared. The laboratory was approximately $12^{\prime} \times 1^{\prime}$, and the experimenter sat four fout in back 
of the subject at a table which held the slide projector and timer. The subject was instructed to road the informed consent sheet which stated the nature of the study and the information that the subject could discontinue participation at any time. After the subject had signed this sheet, the experimenter handed the participant a sheet contrining the task instructions. These instructions were read aloud by the experimenter, and they stated that the task was to "find a four- or five-letter word embedded in the letters without changing the order of them." The subject was also informed that the maximum time alloted each word was $2 \frac{1}{2}$ minutes, and that as soon as the subject called out the word the timing would stop. The participant was asked to spell out each word after calling it out so that there would be no misunderstanding. The experimenter then gave the subject the practice trial, including explicit instructions as to the manner in which it could be solved, and questions were answered at this time.

While this subject was being given the task instructions and completing the practice trial, a confederate (other than the one downstairs administering the JAS) who was the same sex as the subject, was waiting outside the laboratory door. ( No confederate was utilized in the alone condition.) This confederate waited outside the door until $s /$ he heard the experimenter give the subject the practice trial solution and the instruction to do as well on the task as possible. If it was the competition condition, the subject was also told that a competition was being held and that a $\$ 5.00$ prize 
would be awarded to the individual who did the best job on the task. Those in the no competition condition were only told to do as well on tho task as they could.

After the subject was instructed to do as well on the task as possible (and about the $\$ 5.00$ prize if it was the competition condition), those in the inexperienced and experienced peer present conditions then heard a knock on the door.

In the inexperienced peer present conditions, the confederate was at the door and said that $s /$ he was there for the experiment but was early. $\mathrm{s} / \mathrm{he}$ indicated a desire to watch the current subject, and the oxporimenter indicated that it was all right as long as the subject was not disturbed. The experimenter also explained that she didn't mind the future subject observing because " you won't have the same set of word problems, anyway." The confederate then seated her/himself in back and to the right of the subject, clearly out of the subject's view. When the subject finished the task, the experimenter asked the confederate to sit in the next room while she taiked to the subject. In the experienced peer present conditions, the confederate again knocked on the door after hesring the aforementioned cues. In this case, however, the dialogue given by the confederate differed from the inexperienced peer condition. Here, when it was the experienced peor/ competition condition, the confoderate indicated a desire to know how $s /$ he did on the word task compared to other subjects. Aftor the experimenter told the confederate that no comparisons between subjects had boun made, the confederate stated that the task had been 
onjoyable and interesting and asked to watch this subject. The experimenter indicated that the same list of words was not boing utilized, but that the confoderate could reatch as long as $s /$ he was quiet. At the completion of the word task, the confederate excused her/himself, indicating that $s /$ he had an appointment.

The experienced peer/ no competition condition was basically the same as the inexperienced poer/competition condition, only this time the confederate did not ask how s/he did on the word task, but only asked to watch bocause the task had boon intoresting. Again, the confederate excused her/himself at the completion of the task.

In the alone conditions, everything prior to the knock on the door was the same as the above conditions. This time however, there were no interruptions. Again, half of the subjects in this condition were given the competitive instructions and half were not.

In each condition, at the completion of the last word problem, the subject was handed a post-session questionnaire to complete. This was basically a check on the manipulations of the experiment. Upon completion of this, the subject was handed a debriefing sheet and the experimenter explained that the $\$ 5.00$ prize alluded to was actually a manipulation designed to induce competition. The subjects in all conditions were told that individual scores were not actually boing examined and that everyone who participated in the study would have a chance to win $\$ 5.00$, based on a random drawing at the completion of the study. The subject was thanked for her/his participation and asked not to discuss the study with anyone. 
Dependent variables. The dependent variables of interest were latency of response for the 18 trials, the number of nonset responses given in the performance trials and orrors made in the training phase, and the response and latency for the extinction trial. Responses on the post-session questionnaire were also of interest in order to better understand the subjects' perceptions of the experiment.

\section{Results}

\section{Training Trials}

Latencies. A 2 (Type) $\times 2$ (Sex) $\times 2$ (Competition Presence) $\times$ 3 (Peor Presence) X 13 (Trials) repeated measures analysis of variance was utilized to analyze the response latency for the 13 training trials. The main effect of sex was found. to bo statistically significant, $\underline{E}(1,120)=4.52, \underline{2}<.05$. The mean latency for males over the 13 trials ( $\underline{M}=21.16)$ was greater than that for females ( $\underline{M}=15.39)$.

The main effect for trials was also statistically significant, $\underline{F}(12,1440)=10.09, \mathrm{~g}<.001$. Provious research employing this task ( Cohen \& Davis, 1973; Cohen, 1979; Cohen, 1980) has indicated that trials $1,4,8$, and 12 are more difficult and require greater latencies for solutions than the other training trials. A planned comparison between these two sets of trials confirmed this for the present study, $E(1,1440)=78.52, \mathrm{p}<.001$. The mean for trials $1,4,8$, and 12 was 26.99 seconds, while the mean for the rumaining nine trials was 14.40 seconds.

The Trials X Sex X Competition Presence X Peer Presence interaction was also statistically significant, $F(24,2440)=1.64$. $\mathrm{p}<.05$. An inspection of the means ( see Table 2) indicated that this 


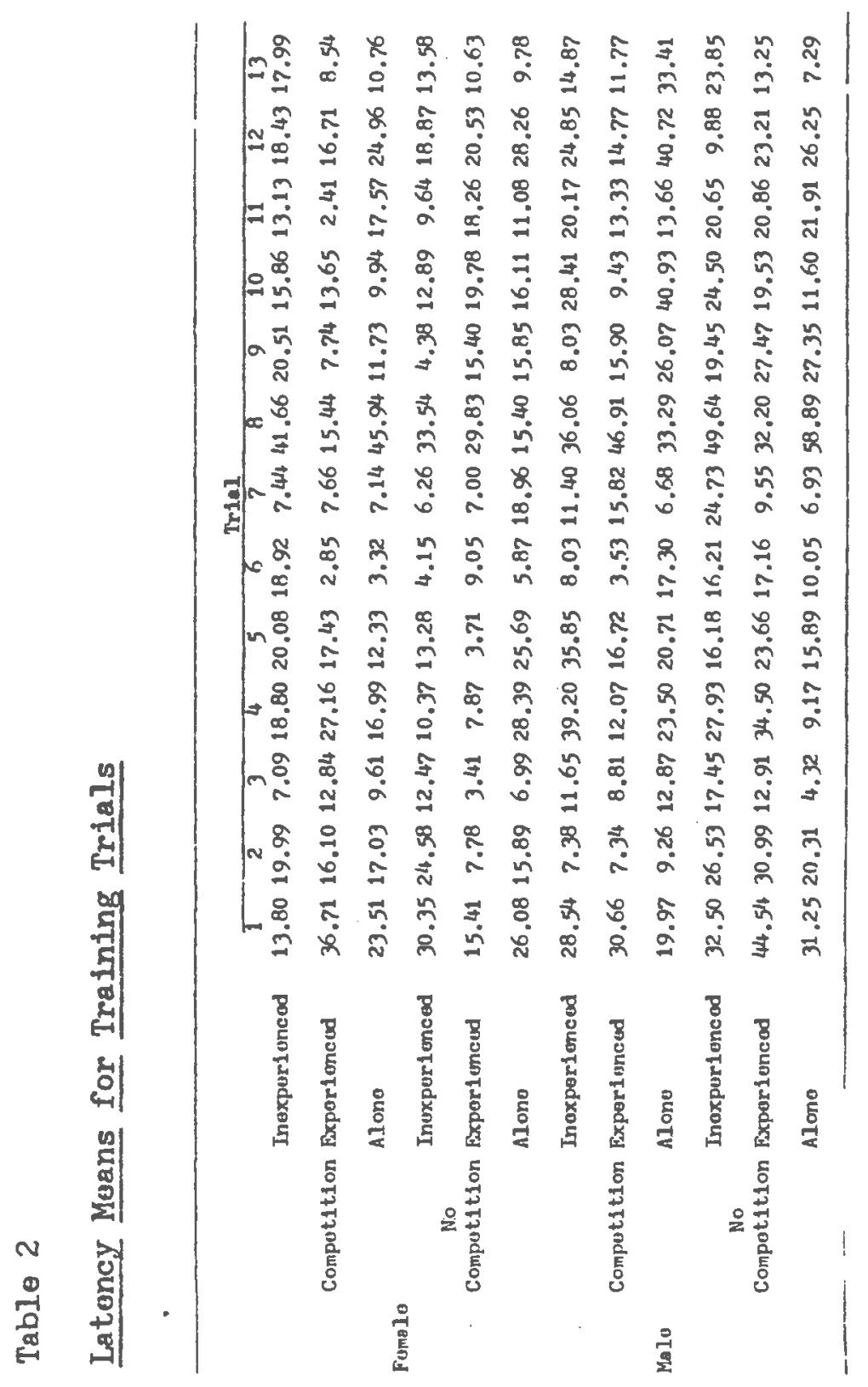


intoraction was not interpretable in any meaningful manner.

Frrors. The number of errors given as a response by the subject wore also analyzed by a $2 \times 2 \times 2 \times 3 \times 13$ repeatod measures analysis of variance. A significant effect of trials was found, $E(12,1440)=$ $9.18, \mathrm{p}<.001$. The average number of correct responses mado on trials $1,4,8$, and $12(1=$ correct, $0=$ incorrect $)(\underline{M}=.809)$ was less than the average number of correct responses made on the other nine trials $(\underline{M}=.931), \underline{F}(1,1440)=13.47, \mathrm{p}<.001$, as assessed by the Scheffé post hoc comparison test.

Performance Trials

Latencies. The latencies for the four performance stimuli were analyzed by a 2 (Type) $\times 2$ (Sex) $\times 2$ (Competition Presence) $X$ 3 (Peer Presence) X 4 (Trials) repeated measures analysis of variance. The main effect of trials was found to be significant, $E(3,360)=$ 14.13. $\mathrm{p}<.001$. The means for the four trials were $6.01,3.67$, 10.28, and 4.06 seconds, respectively. No significant differences were found between the 24 experimental cells.

Solutions. As mentioned previously, the four porformance trials were constructed such that two solutions were possible. Fither the dominant set response or a more direct subordinate response would provide a correct solution to each problem. Utilizing a $2 \times 2 \times 2 \times$ $3 \times 4$ repeated measures analysis of variance, the number of alternative or direct solutions given by the groups were compared. The higher the mean value, the less the dominant set response was given as the solution. 
The Type X Peer Presence interaction was found to be statistically significant, $\underline{E}(2,120)=4.23, \underline{p}<.05$. Type As in the alone condition gave more set responses than did Type As who were observed by an experienced or inexperienced peer. Type Bs in the inexperienced condition gave the most set responses of Bs, followed by those in the experienced peer condition, and the fowest set responses given by Bs were observed in the alone condition.

While Type As' mean solution scores did not differ significantIy across the three peer presence conditions, an inspection of the data suggests a decreasing trend. The greatest number of set responses were emitted in the alone condition $(\underline{M}=.5000)$, followed by the experienced peer condition $(\underline{M}=.5937)$. The inexperienced peer present condition $(\underline{M}=.6146)$ showed the fowest number of set responses. Type Bs showed the reverse pattern with the greatest number of set responses given by those in the inexperienced peer present condition ( $\underline{M}=.5625)$, followed by those in the experienced peer present condition $(\underline{M}=.5729)$ and alone condition $(\underline{M}=.6458)$. The simple effects test indicated that Type As and Bs were significantly different when completing the task alone, $\underline{F}(1,138)=$ $5.92, \mathrm{p}<.05$. The means were .5000 for Type As and .6458 for Type Bs, indicating that Bs broke set and gave more subordinate responses than did Type As ( see Figure 1). Fxtinction Trial

Latency. A 2 (Type) $\times 2$ (Sex) $\times 2$ (Competition Presence) $\times$ 3 ( Peer Prosence) analysis of variance was utilized to analyze the latency for the uxtinction trial. A significant Competition 


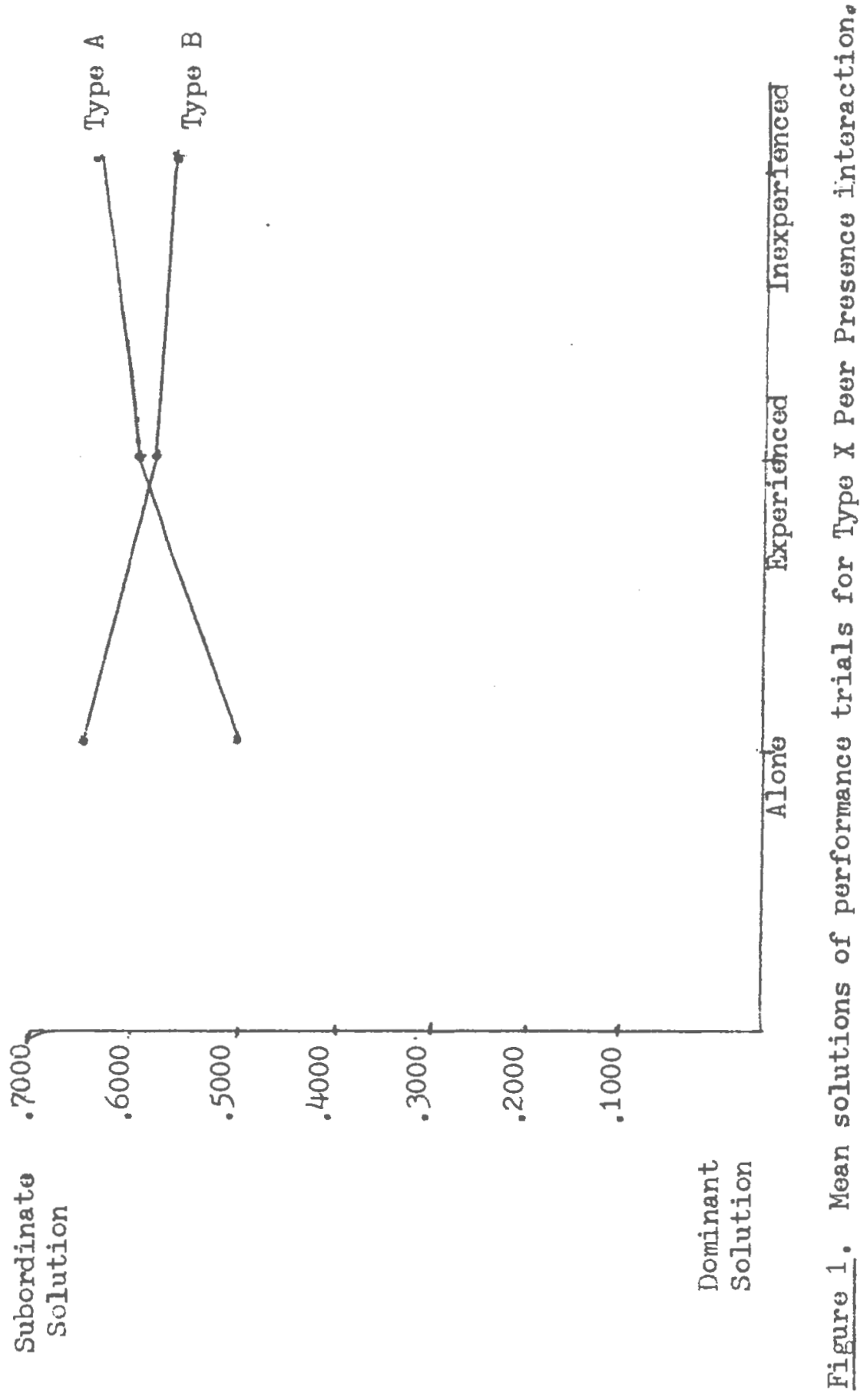


Presence $X$ Poer Presence interaction was found, $\underline{F}(2,143)=$ 4.23. $\mathrm{p}<.05$. For those in the competition conditions, subjects observed by an inexperienced peer took the least time to respond, those alone took longer to respond, and subjects who were in this condition and observed by an experienced peer took the most time to respond. For those subjects who were not given competition instructions, the quickest response was given by those who were alone, followed by subjects who were observed by an experienced peer, and those subjects who were watched by an inexperienced peer took the most time to respond. It was found with the simple effects test that the compotition and no competition groups were significantly different in the inexperienced peer present condition, $\underline{F}(1,138)=4.19, \mathrm{p}<.05$. Those in the inexperienced peer present condition who were not given compotition instructions ( $\underline{M}=23.15)$ took longer to rospond than did those who were given competition instructions $(\underline{M}=9.30)$. Additionally, it was found that the competition and no compotition groups were significantly different in the experienced poer condition as indicated by the simple effects test, $\underline{E}(1,138)=4.31, \mathrm{p}<.05$. It took those in the experienced peer condition who were given competition instructions ( $\underline{M}=24.65$ ) longer to respond than those subjects who wore not given such instructions $(\underline{M}=10.61)$ ( see Figure 2).

Errors. For this trial, the correct response could be found only by breaking set. If the subject continued to use the training set, they would be able to form only a nonsense word. While 12 subjects overall failed to give the correct response on this trial, 


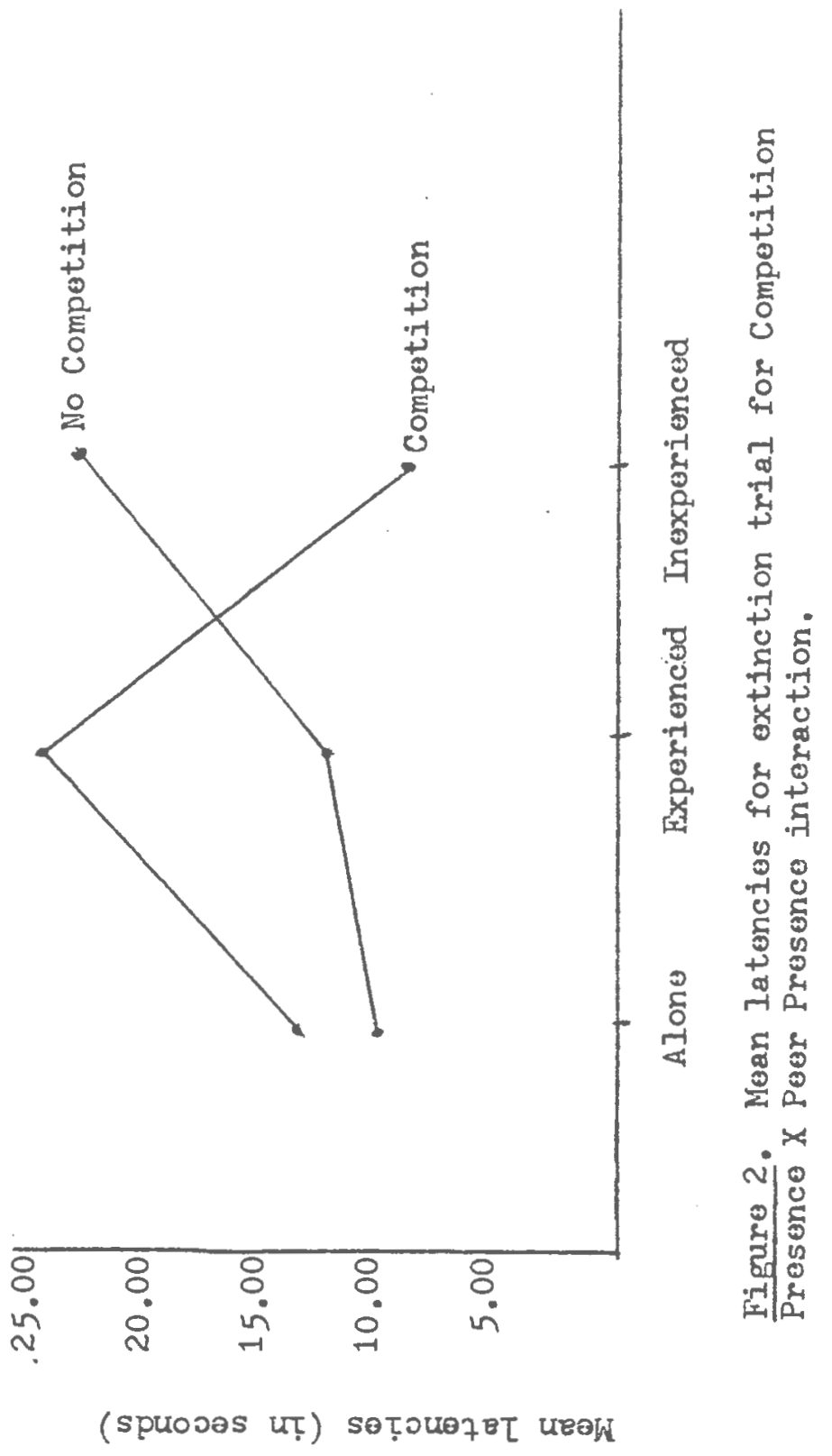


no significant differences were found between any of the conditions. Tablo 3 gives the breakdown of the errors made on this trial across the 24 cells.

\section{Postsession Questionnaire}

Subjects' responses to each of the ten postsession questions were analyzed by seperate 2 (Typo) $\times 2$ (Sex) $\times 2$ (Competition Presence) X 3 (Poor Prosence) analyses of variance. For each of these questions, subjects responded on a 7-point Likert scale, with a score of one indicating "not at all," and a response of seven indicating "extremely." Significant effects wore found for seven of these questions.

For the question asking how interesting the subjects found the hidden-word task, a significant Sex X Competition Presence X Peor Prosence interaction was obtained, $\underline{F}(2,143)=4.59, \mathrm{p}<.05$. Females in the experienced peer/competition condition ( $M=5.67)$ found the task more interesting than did femsles in the experienced peer/no competition condition $(\underline{M}=4.32), \underline{E}(1,132)=7.30, \mathrm{p}<.01$. Males in the inexperienced poer/ competition condition ( $\underline{M}=5.33)$ also found the task more interesting than did males in the inexperienced peer/no competition condition $(\underline{M}=4.33), \underline{F}(1,132)=$ $4.10, p<.05$. Fomales who were alone and given competition instructions ( $\underline{M}=5.42)$ also rated the task as more interesting than did males in the same condition $(\underline{M}=4.25), \underline{F}(1,132)=5.59$. $\mathrm{p}<.05$. Males who wore in the experienced peer/no competition condition. $(\underline{M}=5.33)$ reported that they found the task more 


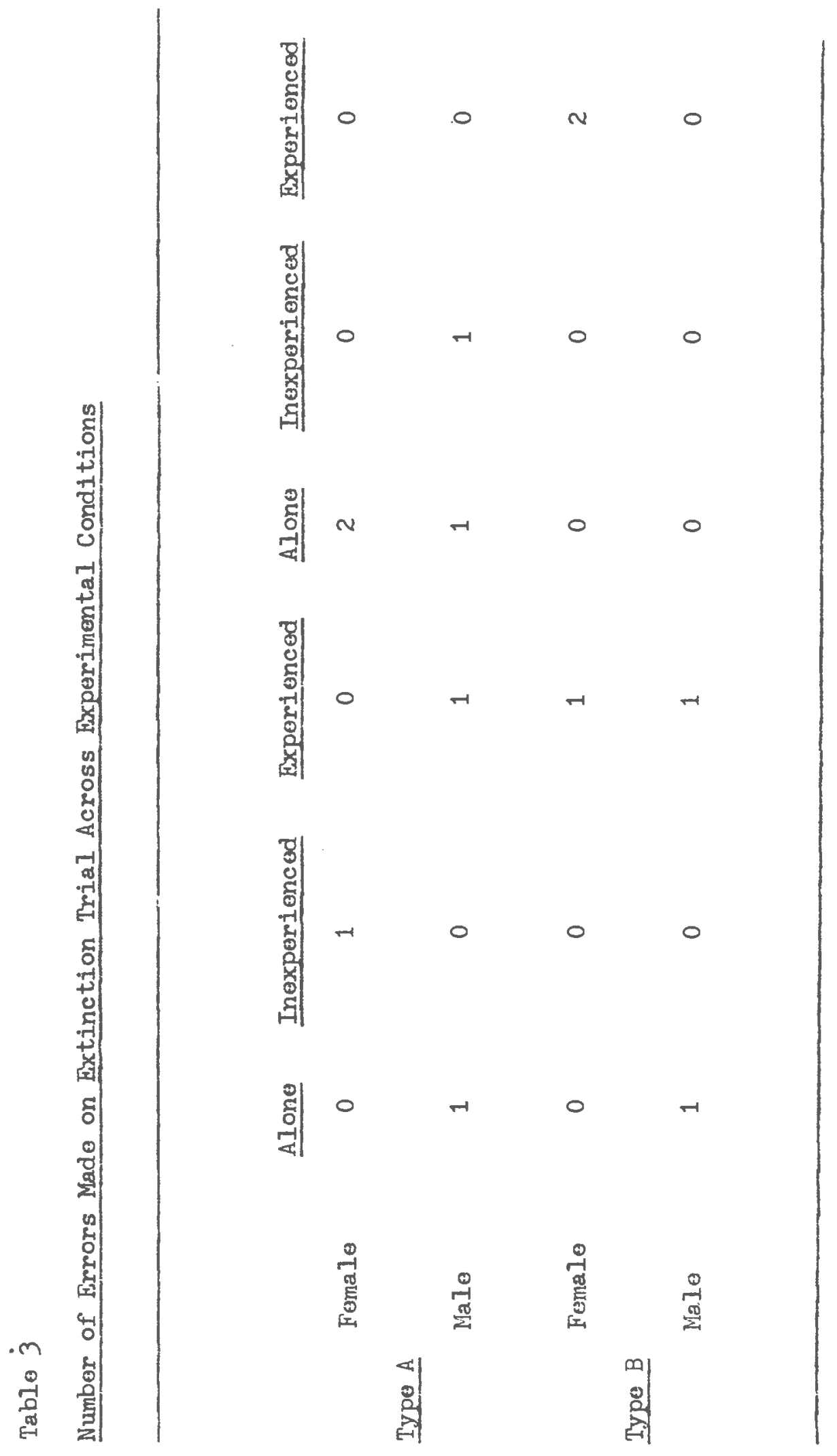


interesting than their female counterparts $(\underline{M}=4.33), \underline{E}(1,132)=$ 4.10, p $<.05$ ( see Table 4).

A main effect for Type was found for three of the questions. These were the following: 1) how competitive did you feel during the word-problems ( not at all competitive-extremely competitive); 2) how difficult did you feel the word problems were ( not at all difficult-extremely difficult); and 3) did you find it difficult to concentrate on the hidden-word problems ( not at all difficultextremely difficult). For the first question, Type As $(\underline{M}=4.37)$ reported foeling more competitive than Bs $(\underline{M}=3.71), \underline{F}(1,143)=$ $7.50, \underline{p}<.01$. Type Bs $(\underline{M}=3.26)$ roported that they found the task more difficult than did As $(\underline{M}=2.86), \underline{F}(1,143)=4.55$, $p<.05$. Type Bs also reported that they found it more difficult to concentrate during the task ( $\underline{M}=2.79)$ than did As $(\underline{M}=2.18)$, $\underline{F}(1,143)=8.36, \mathrm{p}<.01$.

For the question which asked how enjoyable the task was, a Sex X Competition Presence X Peer Presence interaction was found to be statistically significant, $\underline{F}(2,143)=3.24, \mathrm{p}<.05$. Females who were not given competition instructions and were observed by an inexperienced peer $(\underline{M}=4.92)$ found the task more onjoyable than did males in the same condition $(\underline{M}=3.60), \underline{F}(1,132)=6.06$, $p<.05$. Males who were observed by an inexperienced peer and were given competition instructions $(\underline{M}=5.00)$ found the task more enjoyable than did males who were also observed by an inexperienced peer but not given the competition instructions $(\underline{M}=3.60)$, 
Tabla 4

Means for Postsossion Itom: How Interosting Task Was

$\frac{\text { Females }}{\text { Comp No Comp Comp No Comp }}$

$\begin{array}{lllll}\text { Alone } & 5.42 \mathrm{a} & 4.83 & 4.25 \mathrm{a} & 5.00 \\ \text { Fxperienced } & 5.67 \mathrm{~b} & 4.33 \mathrm{bc} & 5.08 & 5.33 \mathrm{c} \\ \text { Inexperienced } & 4.92 & 5.08 & 5.33 \mathrm{~d} & 4.33 \mathrm{~d}\end{array}$

Note. The response scale was a 7-point scale with the value of 1 indicating not at all interesting and the value of 7 indicating extremely interesting. Means with the same subscripts are significantly different from each other.

$$
\begin{aligned}
& { }_{p}<<.05 \\
& b_{p}<.01 \\
& c_{p}<.05 \\
& d_{p}<.05
\end{aligned}
$$


$\underline{E}(1,132)=6.85, \mathrm{p}<.05$.

When asked how competitive they were generally, Type As reported being more competitive $(\underline{M}=4.87)$ than did Type Bs $(\underline{M}=4.18)$, $\underline{F}(1,143)=10.95, g<.01$. Males reported that they were more competitive $(\underline{M}=4.76)$ than did females $(\underline{M}=4.29)$, $\underline{F}(1,143)=$ 5.06, $\mathrm{p}<.05$. There was also a main effect for Competition Presence, with those in the competitive condition ( $\underline{M}=4.74)$ reporting that they were more competitive generally than those in the no competition condition $(\underline{M}=4.32), \underline{E}(1,143)=3.94, \underline{p}<.05$. Additionally, a Type X Competition Presence interaction was found to be statistically significant, $E(1,143)=4.48, \mathrm{p}<.05$. Type As $(M=5.31)$ who were in the competitive conditions reported that they were more competitive than did As in the no competition conditions ( $\underline{M}=4.44)$. $\underline{F}(1,140)=8.53, \underline{p}<.01$. Type Bs in the competition.condition ( $\underline{M}=4.17)$ did not report being more competitive than Bs in the no competition condition ( $M=4.11$ ). Type As in the competitive condition ( $\underline{M}=5.31$ ) also rated themselves as being more competitive than did Type Bs in the same condition $(\underline{M}=4.17), \underline{F}(1,140)=$ $14.91, \pm<.001$.

For the question asking how important it was for them to do well on the task, main effects for Type and for Sex were found to be statistically significant. Type As $(\underline{M}=4.90)$ reported that it was more important for them to do well than did Type Bs $(\underline{M}=4.33)$, $\underline{F}(1,143)=5.86, \underline{p}<.05$. Females $(\underline{M}=5.04)$ also found it more important to do well than did males $(\underline{M}=4.19), \underline{F}(1,143)=12.98$, 
p <.001. A Type X Sex X Competition Presence interaction was also found to be statistically significant, $\mathrm{F}(1,143)=5.86, \mathrm{p}<.05$. Type A females who were in the competitive conditions ( $M=5.56$ ) reported that it was more important for them to do well on the task than did Type $B$ females ( $M=4.61$ ) who were in the same condition, $\underline{F}(1,136)=8.12, \underline{p}(.01$. Type A males $(\underline{M}=4.83)$ in the no competition condition reported that it was more important for them to do well on the task than did the Type B males $(M=3.50)$, $\underline{F}(1,136)=10.28, \mathrm{p}<.01$ ( soe Tablo 5).

Table 5

Means for Postsession Item: How Important It Was to Do Well

\begin{tabular}{lllll}
\hline & \multicolumn{2}{c}{ Type A } & & Type B \\
\cline { 2 - 5 } & Females & Males & & Females Males \\
Competition & $5.56_{\mathrm{a}}$ & 4.22 & $4.61_{\mathrm{a}}$ & 4.22 \\
No Competition & 5.00 & $4.83_{\mathrm{b}}$ & 5.00 & $3.50_{\mathrm{b}}$ \\
\hline
\end{tabular}

Note. The response scale was a 7-point scale with the value of 1 indicating not at all important and the value of 7 indicating extremely important. Means with the same subscript are significantly different from each other.

$$
\begin{aligned}
& { }^{2} p<.01 \\
& b_{p}<.01
\end{aligned}
$$


Discussion

The intent of the present study was to extricate competition from distraction, in order to oxamine the cause of social facilitation for Type A individuals. Gastorf et al. (1980) demonstrated that Type As showed social facilitation effects while in the presence of either a similar or suporior coactor and intimated that distraction-conflict was the cause. However, competition was implied in the instructions to subjects working in the coacting conditions, so it was not possible to ascertain what was responsible for the facilitation effects. The present study extricated competition by including it as a factor, and examined Type As in the audience paradigm rather than the coacting one used by Gastorf et al. (1980). An attempt was also made to manipulate the perceived ability or knowledge of the observer regarding the task being completed by the subject. This was done by the observer describing hor/himself as someone who had already completed the task or as one who would soon complete it. It was believed that this would parallel the superior and similar coactors of Gastorf et al. (1980).

Based on the Gastorf et al. (1980) study, it was predicted that Typo As would show greater social facilitation offocts than Type Bs. This was observed, but not as originally oxpected. More specifically, Type As who completed the task in the alone condition gave significantly more set responses than did Bs under the same condition, indicating social facilitation. One must recall that the experimenter sat beind the subject in all conditions to work the slide projector 
and record responses and latencies. While it was believed that the experimenter was unobitmusive and that subjects would experience the situation as if alone, an alternative is now proposed.

It now seems that the present study actually contained no true alone condition with which to compare the audience presence situations. This explains why neither As' nor Bs' performance in the alone condition differed from their respective performance in the audience presence conditions. However, it is possible that Type As perceived the alone condition differently than did Type Bs, perhaps seeing the experimenter as an evaluator and wanting to impress her. Some support for this is derived from the mean solution scores of Type As on the performance trials. Specifically, Type A individuals showed a decreasing trend in set responses across the alone, experienced peer, and inexperienced peer conditions, respectively. What appears to occur is a reduction of salience of a high-powered evaluator ( experimenter) when a less powered evaluator (experienced peer) is present, and the greatest reduction occurs when the least powerful ( inexperienced peer) individual is present. This process is completely reversed for Type Bs. It has been reported that Type As are more interested in securing the respect of a single superior than that of a scoro of their peers (Friedman \& Rosenman, 1974, p. 92). In this situation, the experimenter could have been viewed as a "superior" by Type As, in that she had had an opportunity to witness several subjects complete the task and 
had the necessary knowledge to evaluate the subjects' performances. Type Bs, on the other hand, may have been loss concerned with the oxperimenter's presence.

While Gastorf et al. (1980) found that their Type A subjects reported being more distracted than the Type Bs did, in the present study there were no differences found when subjects were asked how distracted they had been. Howerer, when the question was stated differently, and subjects were asked how difficult they found it was to concentrate during the task, Type Bs reported that they found it more difficult to concentrate than. did Typo As. Although this is not consistent with the Gastorf ot al. (1980) study, it is consistent with the findings of Matthews and Brunson (1979), who observed that Type As actively suppress their attention to peripheral events irrelevant to the task at hand. Therefore, in light of these speculations using the audience paradigm, it appears that distraction-conflict was not the mediating factor in affecting the performance of As in the alone condition, but rather that something more akin to evaluation apprehension was responsible.

With regard to the competition manipulation, it was predicted that when the task was competitive it would lead to greater social facilitation effects. It was further believed that this would particularly be the case with Type As, who reportedly are spurred on by competition (Gotay, 1981). It was found that on the extinction trial, those subjects given competition instructions who were observed by a peer who would soon complete the task took 
less time to respond than subjects in that condition who were not given the instructions. Conversely, those individuals given competition instructions who were observed by a peer who was said to have already completed the task took longer to respond than did those not given the instructions. No effects involving the competition factor were found in the performance phase of the study. However, it is possible that whon a word stimulus was presented that could not be solved by maintaining set (extinction trial), the competition instruction became more saliont, leading to improved performance and hoightened arousal for those who were observed by an inexperienced peer. On the other hand, being observed by a peer who had already completed the task and had the knowledge to judge the subject's performance and was competing with the subject for $\$ 5.00$, may have been too arousing, thus leading to poorer performance of subjects in this condition. With regard to As and the competition manipulation, it was found that the Type As did not exhibit the expected social facilitation effects when competition was inducod. Instead, the Typo As seemed to feel competitive under all conditions, as indicated by the postsession questionnaire item. Therefore, it appears that in the present study, As did not discriminate betwoen the situation in which compotition was spocified and that in which it was not, but even when feeling competitive, their performance was not markedly different than Type Bs'. 
It appears from this study then, that for Type As, neither distraction-conflict nor induced competition lod to social facilitation effects that were greater than Type Bs'. In fact, if one looks at the situation in which performance differences were found between As and Bs, it is suggested that As were responding to the presence of the experimenter who was in the best position to evaluate the performance of the subject in relation to all other subjects who had completed the task. In the realm of the Gastorf ot al. (1980) study, it may also bo that Typo A subjects there exhibited social facilitation offects because of the perception that their performance was being evaluated by their coactors, whether similar or superior. However, neither that study nor the present study contained any measures that would tap this perception. Further research examining this possibility is necessary. It may be that Type As see themselves as being evaluated by others oven when the situation is not explicitly evaluative in nature, while Type Bs can discriminate situations more readily. In addition to the foregoing, a truly alone condition would have utility for clearly examining audience effects. The speculation on the reduction of evaluator salience also needs to be examined experimentally in future research. 
References

Bond, C.F., Jr. (1982). Social facilitation: A self-presentational viow, Journal of Personality and Social Psychology, 42 (6), $1042-1050$

Carver, C.S. \& Scheier, M. F. (1981). The solf-attention-inducerd feodback loop and social facilitation. Journal of Experimental Social Psychology, 17, 545-568.

Cohen, J. L., \& Davis, J. H. (1973). Effects of audience status, ovaluation and time of action on performance with hidden-word problems. Journal of Personality and Social Psychology, 27 (1), $74-85$.

Cohen, J.I. (1979). Increased evaluation apprehonsion through permenency of record. Motivation and Fmotion, 3, 19-33. Cohon, J. I. (1980). Social facilitation: Audienco versus evaluation apprehension effects. Motivation and Emotion, 4, 21-34. Cottrell, N. B. (1968). Performance in the presence of other human beings: More prosence, audience, and affiliation effects. In E. C. Simmel, R. A. Hoppe, \& G. A. Milton (Eds.). Social facilitation and imitative behavior. Boston: Allyn and Bacon. Cottrell, N. B. (1972). Social facilitation. In C. G. McClintock (Ed.), Experimental social psychology. New York: Holt, Rinehart, \& Winston.

Cottrell, N. B., wack, D. I., Sekerak, G. J., \& Rittlo, R. H. (1968). Social facilitation of dominant responses by the presence of an 
audience and the mere presence of others. Journal of Personality and Social Psychology, 9, 245-250.

Elliott, E. S., \& Cohen, J. I. (1981). Social facilitation effects via intorpersonal distance. Journal of Social Psychology, 114, $237-249$

Friedmen, M., \& Rosenmen, R. H. (1959). Association of specific overt behavior pattern with blood and cardiovascular findings. Joumal of the American Medical Association, 169, 1286-1296. Friedman, M., \& Rosenman, R. H. (1974). Typo A behavior and your hoart. New York: Knopf.

Gastorf, J., Suls, J., \& Sanders, G. (1980). Type A coronary-prone bohavior pattern and social facilitation. Journal of Personality and Social Psychology, 38 (5), 773-780.

-Glass, D. C. (1977). Behavior patterns, stress, and coronary disease. New Jersey: Lawrence Erlbaum. Gotay, C. C. (1981). Cooperation and competition as a function of Typo A behavior. Personality and Social Psychology Bulletin, I. (3), 386-392.

Henchy, T., \& Glass, D. C. (1968). Evaluation apprehonsion and social facilitation of dominant and subordinato responses. Journal of Personality and Social Psychology, 10, 446-454. Jenkins, C. D., Rosenman, R. H., \& Zyzanski, S. J. (1974). Prediction of clinical coronary heart disease by a test for the coronary-prone behavior pattern. The New England Journal of Medicine, 290 (23), 1271-1275. 
Kenigsberg, D., Zyzanski, S. J., Jonkins, C. D., Wardwell, W. T., \& Licciardello, A. T. (1974). The coronary-prone behavior pattern in hospitalized patients with and without coronary heart disease. Psychosomatic Medicine, 36, 344-351.

Krantz, D. S., Glass, D. C., \& Snyder, M. L. (1974). Helplessness, stress level, and the coronary-prone behavior pettern. Journal of Experimental Social Psychology, 10, 284-300.

Markus, H. (1978). The effect of mere presence on social facilitation: An unobtrusive test. Journal of Experimental Social Psychology, 14, 389-397.

Matthows, K. A., \& Brunson, B. I. (1979). Allocation of attention and the Type A coronary-prone behavior pattern. Journal of Personality and Social Psychology, 37, 2081-2090. Triplett, N. (1897). The dynamogenic factors in pacemaking and competition. American Journal of Psychology, 9, 507-533. Zajonc, R. B. (1965). Social facilitation, Science, 149, 269274.

Zajonc, R. B., \& Sales, S. M. (1966). Social facilitation of dominant and subordinate responses. Journal of Fxperimental Social Psychology, 2, 160-168. 
Appendix

Jenkins Activity Survey

This questionnaire will ask how you react to some everyday situations. Our interest is in what is true for you, and since there are no "right" or"wrong" answers, please try to be as frank as possible. Please do not ask anyone how to respond to the items, because we are interested in how YOU would answer. Please do not write on the questionnaire and put all of your answers on the accompanying answor sheet by indicating the appropriate letter ( $a, b, c$, otc.). Please make sure that you anwer all 44 questions on the questionnaire. All responses will be considered confidential and no data will be released in which individuals could be identified.

Thank you for your cooperation and assistance in this project. 
1. Do you over have trouble finding time to get your hair cut or styled?
a. Never.
b. Occasionally.
c. Almost always.

2. Does colloge stir you into action?
a. Less often than most college students.
b. About average.
c. More often than most college students.

3. Is your everyday life filled mostly by
a. Problems needing solutions.
b. Challenges noeding to be met.
c. A rathor predictable routine of ovents.
d. Not enough things to keep me interested or busy.

4. Some poople live a calm, predictable lifo. Others find themselves often facing unexpected changes, frequent interruptions, inconveniences or "things going wrong." How often are you faced with these minor (or major) annoyances or frustrations?
a. Sevoral timos a day.
b. About onco a day.
c. A few times a week.
d. Once a woek.
$\theta$. Once a month or less.

5. When you are under pressure or stress, do you usually
a. Do something about it immediately.
b. Plan carefully before taking any action.

6. Ordinarily, how rapidly do you oat?
a. I'm usually the first one finished.
b. I eat a little faster than averago.
c. I eat at about the same sperd as most people.
d. I eat more slowly than most people.

7. Has your spouse or some friend over told you that you eat too fast?
a. Yes, often.
b. Yes, once or twice.
c. No, no one has told me this. 
8. How often do you find yourself doing more than one thing at a time, such as working while eating, reading while dressing, figuring out problems while driving?

a. I do two things at once whenever practical.

b. I do this only when I'm short of time.

c. I rarely or never do more than one thing at a time.

9. When you listen to someone talking and this person takes too long to come to the point, do you feel like hurrying him along?

a. Froquently.

b. Occasionally.

c. Almost never.

10. How often do you actually "put words in his mouth" in order to spoed things up?

a. Frequently.

b. Cccasionally.

c. Almost never.

11. If you tell your spouse or a friend that you will meet them somewhere at a definite time, how often do you arrive late?
a. Once in a whilo.
b. Rarely.
c. I am nover late.

12. Do you find yourself hurrying to got places oven when there is plenty of time?
a. Often.
b. Occasionally.
c. Rarely or never.

13. Suppose you are to meet someone at a public place (streot corner, building lobby, restaurant) and the othor porson is already 10 minutos lato. Will you

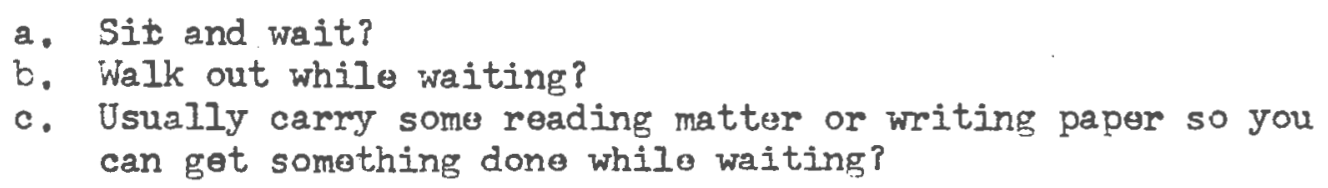


14. When you have to "wait in line," such as at a restaurant, a store, or the post office, do you

a. Accept it calmly?

b. Feel impatient but do not show it?

c. Foel so impatient that someone watching could tell you were restless?

d. Refuse to wait in line, and find ways to avoid such delays?

15. When you play games with young children about 10 years old, how often do you purposely let them win?

a. Most of the time.

b. Half the time.

c. Only occasionally.

d. Never.

16. Do most people consider you to be
a. Definitely hard-driving and competitive?
b. Probably hard-driving and competitive?
c. Probably more relaxed and easy going?
d. Definitely more relaxed and easy going?

17. Nowadays, do you consider yourself to be
a. Definitely hard-driving and competitive?
b. Probably hard-driving and competitive?
c. Probably more relaxed and easy going?
d. Definitely more relaxed and easy going?

18. How would your spouse ( or closest friend) rate you?
a. Definitely hard-driving and competitive.
b. Probably hard-driving and competitive.
c. Probably more relaxed and easy going.
d. Definitely more relaxed and easy going.

19. How would your spouse (or best friend) rate your general lovel of activity?

a. Too slow. Should be more active.

b. About average. Is busy much of the time.

c. Too active. Needs to slow down. 
20. Would people who know you well agree that you take your work too seriously?

a. Dofinitely yos.

b. Probably yes.

c. Probably no.

d. Definitely no.

21. Would people who know you well agree that you have less energy than most people?

a. Definitely yes.

b. Probably yes.

c. Probably no.

d. Definitely no.

22. Would poople who know you well agreo that you tend to get irritatod easily?

a. Definitoly yos.

b. Probably yos.

c. Probably no.

d. Dofinitely no.

23. Would people who know you well agree that you tend to do most things in a hurry?

a. Definitely yos.

b. Probably yes.

c. Probably no.

d. Dofinitely no.

24. Would people who know you well agree that you enjoy "a contest" (competition) and try hard to win?

a. Definitely yes.

b. Probably yos.

c. Probably no.

d. Definitely no.

25. Would people who know you well agree that you get a lot of fun out of your life?

a. Definitely yes.

b. Probably yos.

c. Probably no.

d. Definitoly no. 
26. How was your "temper" when you were younger?

a. Fiory and hard to control.

b. Strong but controllable.

c. No problem.

d. I almost never get angry.

27. How is your "temper" nowadays?

a. Fiory and hard to control.

b. Strong, but controllable.

c. No problem.

d. I almost never get angry.

28. When you are in the midst of studying and someone intermupts you, how do you usually feel inside?

a. I feel O.K. because I work better after an occasionaI break.

b. I feel only mildly annoyed.

c. I feel really irritated because most such intermuptions are unnecessary.

29. How oftem are there deadlines in your courses? (If deadlines occur irregularly, ploaso circle the closest answer below).

2. Daily or more ofton.

b. Woekly .

c. Monthly.

d. Never.

30. Do these deadlines usually

a. Carry minor pressure because of their routine nature?

b. Carry considerable pressure, since delay would upset things a great doal?

31. Do you ever set deadlines or quotas for yourself in courses or other things?

a. No.

b. Yes.

c. Yes, once per woek or more often.

32. When you have to work against a deadline, is the quality of your work

a. Better?

b. Worse? 
c. The same? (Pressure makes no difference)

33. In school do you ever keep two projects moving forward at the same time by shifting back and forth rapidly from one to the other?
a. No, never,
b. Yes, but only in emergencios.
c. Yes, regularly.

34. Do you maintain a regular study schedule during vacations such as Thanksgiving, Christmas, and Faster?
a. Yes.
b. No.
c. Sometimes.

35. How often do you bring your work home with you at night or study materials related to your courses?
a. Rarely or never.
b. Occasionally (less than once a week).
c. Once or more a weok.

36. When you find yourself getting tired wille studying, do you usually
a. Slow down for a while until your strength comes back.
b. Keep pushing yourself at the same pace in spite of the tiredness.

37. How ofton do you go to the university whon it is officially closed (such as nights or woekends)? IF this is not possiblo, circle here: 0
a. Rarely or never.
b. Occasionally (less than once a weok).
c. Once or more a week.

38. When you are in a group, do the other people tend to look to you to provide leadership?
a. Rarely.
b. About as often as they look to others.
c. More often than they look to others. 
39. Do you make yourself written lists of "things to do" to help you remember what noeds to be done?
a. Never.
b. Occasionally.
c. Frequently.

IN EACH OF THE FOLIOWING QUESTIONS, PLEASE COMPARE YOURSELF WITH THE AVERAGE STUDENT AT YOUR UNIVERSITY.

40. In amount of effort put forth, I give
a. Much moro offort.
b. A little more effort.
c. A little less effort.
d. Much less effort.

41. In sense of responsibility, I am
a. Much more responsible.
b. A little more responsible.
c. A little less responsible.
d. Much less responsible.

42. I find it necessary to hurry
a. Much more of the time.
b. A littlo more of the time.
c. A little loss of the time.
d. Much less of the time.

43. In being precise (careful about detail), I am
a. Much more precise.
b. A little more precise.
c. A little less precise.
d. Much less preciso.

44. I approach life in general
a. Much more seriously.
b. A little more serionsly.
c. A little less soriously.
d. Much less soriously. 